\title{
STRATEGIES AND POLICIES FOR NEW TECHNOLOGIES: THE UNITED NATIONS, THE UNITED STATES AND THE EUROPEAN UNION
}

\author{
Alina ALEXANDRU \\ "Carol I" National Defence University, Bucharest, Romania \\ alinaalexandru0202@gmail.com
}

\begin{abstract}
New technologies have marked the beginning of the Forth Industrial Revolution era. While the advantages of new technologies for our day-to-day life are undeniable, we cannot fail to notice that emerging and disruptive technologies also imply challenges and risks for individuals, societies and countries. Moreover, in the absence of regulations and norms internationally accepted and assumed, risks associated to the misuse of new technologies tend to increase, transforming the domain into a competition arena. States and international organizations perceive the pressure to address emerging technologies. The United Nations, the United States and the European Union have defined their own strategies and policies on the new technologies with the aim at capitalizing the benefits and minimizing the risks. While different in their view, UN's, US' and EU' strategies and policies offer landmarks to consider in addressing new technologies.
\end{abstract}

KEYWORDS: new technologies, strategy, policy, the United Nations, the United States, the European Union

\section{Introduction}

During the past years we have increasingly benefited of the unprecedented technological development so that, today, one ca hardly imagine day-to-day life without technology "assistance", whether we refer to communications, digitalization, internet of things or any other dimension of the new technologies.

Rapid development along with exponential growth of the emerging technologies' effectiveness and added value to numerous domains, such as social, economy, industry, and military, have entitled the assessment that we are actually witnessing "the Forth Industrial Revolution". After identifying and making use of the revolutionary features of steam power and waterpower following 1760, telegraph networks and electricity after 1871, and computer and communication technologies following World War II, the second decade of the 2000s has brought to the word the advantages of computerization of manufacturing. Klaus Schwab, founder and executive chairman of the Word Economic Forum, contradicting the hypothesis that we are witnessing a prolongation of the Third Industrial Revolution, indicates three characteristics of the current technological development, namely "velocity, scope and systems impact" (Schwab, 2016), which point to the Forth Industrial Revolution due to their influence on the system of production, management and governance. 
The dynamic resulting from the development of new technologies, which involves both benefits and challenges, has highlighted the importance of innovation and strategic approach to keep pace with it, as well as the need for regulations and defensive tools to prevent malicious use of the new technologies that can affect the security and safety of the society and state.

Against this background, emerging and disruptive technologies have become increasingly high on the political agenda of states and international organizations.

The most advanced countries have already developed dedicated strategies and seek to set the framework of the emerging and disruptive technologies domain. In practical terms, states and companies examine ways to internalize, make use of and improve technological assistance, depending on their phase of development, to augment positive outcomes in numerous domains of activity.

Paul Armstrong in "Disruptive Technologies: Understand, Evaluate, Respond", observing the changes drawn by the technologies in individuals' needs, compared to Maslow's Hierarchy of Needs, emphasizes the importance of considering the impact on and the interaction with human, when projecting technological changes as they usually draw changes in individuals' behaviour as well. Thus, he outlines that initial analysis on projected technologies should point to clear advantages and minimum negative impact of new technologies (Armstrong, 2017).

However thorough the analysis may be, indicating mostly positive outcomes of new technologies, unforeseen effects would always remain out of sight and different actors would attempt to identify possibilities of malicious use so that the disruptive capacity of emerging technologies represents an intrinsic part of this vast domain. Therefore, the development and implementation of strategies comprising a defensive component, designed to prevent and counter risks and threats originating from disruptive technologies, become imperative.

As reality has shown us, the great challenge in dealing with new technologies is to maximize the benefits, in the sense of common good, while minimizing the risks, especially the malicious use or the misuse of technology provoking unintentional negative consequences. For example, the social media networks facilitate the connection between people worldwide and common action towards shared beneficial ends but, at the same time, the social networks serve as means to promote hatred and disinformation, affecting numerous people. The most recent relevant example is the COVID-19 pandemic context when unauthorized opinions rapidly spread worldwide affecting people's perceptions and choices to their disadvantage despite official and authorized advice regarding the implications. Automation and artificial intelligence also facilitate economic growth but they will severely affect people as well, especially in terms of employment.

At the same time, ensuring cybersecurity has become an imperative difficult to achieve due to the increase of this type of threats originating from both state and nonstate actors along with the complexity required to identify the sources of attack.

Confronted with the massive assault of new technology in their day-to-day life, people are increasingly vulnerable and inappropriately protected by norms, state and institutions.

In terms of societies, the risks associated to disinformation and massive manipulation via social networks may generate even violent behaviours of large communities, and thus instability and insecurity.

Elevating the level from individuals and society to countries, we can assess that states poorly equipped to face the development of new technologies will be severely affected, while the discrepancy 
between those countries and the high-tech developed ones will deepen even more.

Against this background, we can summarize that the management of emerging and disruptive technologies requires two distinct approaches. One is proactive, designed to capitalize the advantages of the new technologies and make use of them as a means to wider the advance ahead competitors or reduce the difference, depending on the case, by permanent update and development of the innovation sector. Another approach is reactive, focused on the defensive and responsive component designed to prevent and counter concrete and potential risks and threats generated by the malicious use of the new technologies.

Both approaches, proactive and reactive, should be distinctive but interconnected, based on engagements and coordination at the political, societal, economic and military levels, as well on a tight cooperation between institutions and between state and the public sector and society as a whole.

As mentioned above, several states and organizations have elaborated strategies in their endeavour to address the opportunities and challenges implied by the new technologies.

In the following, we will present the main characteristics of the strategies on the new technologies of the United Nations, the United States and the European Union.

\section{United Nations Secretary-} General's Strategy on New Technologies

The United Nations (UN) issued "Secretary-General's Strategy on New Technologies" in September 2018 with the aim at sustaining the developments in this domain so that they can benefit UN objectives set up by the 2030 Sustainable Development Agenda.

At the same time, the Strategy is intended to support the conformity of new technologies' development with the principles and values of the UN Charter, human rights and international law, having as guiding principles to "protect and promote global values; foster inclusion and transparency; work in partnership; build on existing capabilities [...]; and [...] continue to learn" (United Nations, 2018).

The United Nations is aware of the vast implications of the new technologies for individuals, societies, states and organizations, as well as of its own shortfalls regarding the involvement in this domain and its need to modernize and adjust to the new developments in the international environment. Therefore, by this Strategy, UN intends to set the framework and direct the endeavour of the organization and its member states in this domain towards the common good and responsible use of new technologies.

To this aim, UN strategy puts a great emphasize on the inclusive dialog and cooperation with all relevant actors to reach an agreement largely assumed regarding "the principles, values, obligations, and responsibilities that should guide the design, development and uses of the technologies" (United Nations, 2018, p. 9).

The high representative level of the United Nations for the rules-based international order requires the organization to assume a stance and offer a leading example for the international endeavour of addressing the new technologies.

The UN admits that the main responsibility of managing new technologies lies with the governments and their respective societies. Considering its prerogatives, the United Nations assumes to play an important role in stimulating and supporting states and stakeholders to set up the international policy and norms so that they ensure the beneficial use of new technologies for all and minimum risk for society, economy and security.

In terms of concrete action, the United Nations' Secretary-General commits to (United Nations, 2018, p. 13): 
- deepen internal capacities and exposure to new technologies, seen as a means to increase connection with developments in this domain, including by the United Nations' Innovation Network, and to tighten cooperation with state and non-state actors facing technologic adaptation;

- increase understanding, advocacy and dialog by capitalizing the unique global power of the United Nations to promote the use of new technologies in accordance with the common global values, while addressing the need to mitigate the risks and avoid augmented inequality;

- support dialog on normative and cooperation frameworks, making use of the United Nation's recognized value as a trust building platform to strengthen cooperation and coordination at different levels in order to ensure that the new technologies are heading towards the right direction and the shared desired outcome reflecting the international recognized values and principles;

- enhance the United Nations system support to government capacity development, with a particular focus on addressing the needs of the states concerned and challenges by the development of new technologies, in order to reduce the gap in comparison with high-tech ones and create favourable conditions to agree and sustain solutions for the common benefit.

By this Strategy, the United Nations intends to make an important step in approaching the domain of the new technologies and the requirements implied by it. Based on the effectiveness and/or shortfalls identified, the Strategy will be revised to enhance culture of innovation and to support global endeavour.

\section{The United States' National Strategy for Critical and Emerging Technologies}

The United States' President released "The National Strategy for Critical and Emerging Technologies" in October 2020. Having as basis the US' global leadership in critical and emerging technologies, the Strategy defines two main directions of action aimed at preserving and reinforcing this status, namely the promotion of the national security innovation base and the protection of US' technology advantage.

As stated in the Introduction, the national strategy is motivated by the "growing challenges from strategic competitors" (The President of the United States, 2020) attempting to surpass the US' leadership in certain domains of new technologies.

The promotion and protection of the national security innovation base represents an objective assumed by the United States in the National Security Strategy as part of the greater effort to protect the American prosperity and way of life and to enhance US' global influence in the present increasingly competitive international environment.

The United States regard China as a major concern due to its global ambitions and its unfair and assertive behaviour which includes misappropriating technology, intellectual propriety abuse, undermining fair market competition and democratic values.

In terms of new technologies' use the US is particular concerned with the Chinese military-civil fusion strategy which implies the use of emerging and disruptive technologies in the military domain. At the same time, the US observers Russia's aggressive conduct in the new technologies domain and its focus on military and dualuse with the aim at developing the Russian military power by civil-military integration.

Confronted with these challenges, the US is resolute to preserve the world leadership in in critical and emerging technologies, while continuing to cooperate with allies and partners and managing national security risks related to emerging and disruptive technologies.

An important line of action will focus on the domestic endeavour to ensure US' technological advance by internal measures 
and actions, to include encouraging the private sector to consider the national implications of new technologies' development.

Admitting that US' advance in all domains of critical and emerging technology is not feasible, the US assumes to ensure the lead "in the highest-priority technology areas" (The President of the United States, 2020, pp. 2-3), while continuing to cooperate with allies and partners in high-priority technology domains.

Concreate actions to implement "The National Strategy for Critical and Emerging Technologies" cover two pillars (The President of the United States, 2020, pp. 5-10) specifically:

- promote the national security innovation base, with a focus on stimulating innovation by all means, ensuring high quality of experts, adapting national policies and regulations, and engaging in drawing the international norms and standards, increase research and development financing, promote cooperation between the public and private sectors domestically and with allies and partners worldwide in support of democratic values;

- protect the United States' technology advantage by implementing an ample set of measures and actions to:

- Ensure fairness and reciprocity;

- Enforce agreements and norms, based on common principles assumed;

- Counter illicit means targeting the US' research and development sector;

- Promote research security;

- Develop cooperation with the private sector to improve awareness regarding critical and emerging technologies;

- Monitor international developments of new technologies and assess their impact on the US;

- Secure the supply chains;
- Increase cooperation internally, as well as with allies and partners worldwide to counter hostile actions on US national security innovation base or on their respective component.

We can summarize that the United States focuses the national endeavour related to the development of critical and emerging technologies guided by three major objectives, namely to ensure its superiority in the most important domains of new technologies, to cooperate with allies and partners in the important ones and to manage the risks related to critical and emerging technologies.

\section{European Union and Europe's Digital Decade}

The European Union (EU) regards the development of new technologies as a great opportunity to build a European digital society for the benefit of the European citizens and businesses, while advancing EU' major aim of increasing the Union' strategic autonomy.

The reflection process on the European digitalization, namely "Digital Compass: The European Way for the Digital Decade" identifies four main objectives to follow: the development of the European citizens' digital abilities, to include highly qualified experts in this domain, ensuring and securing the digital infrastructure, adapting the European businesses to the digital area, and the digitalization of public services (European Commission, 2021). In order to achieve these objectives, the European Union will develop policies in the domains of cloud computing, artificial intelligence, big data and connectivity.

The Policy Programme: "A path to the Digital Decade" will guide the general effort of the EU's digitalization by its specific targets on the four objectives (European Commission, 2021) mentioned above for 2030. 
In terms of digital ability and professionalization, the EU aims at a $24 \%$ increase of European adults' ability to use digital tools, and 11.6 million more specialists employed in the information and communications technology domain.

With regard to the digital infrastructure, the EU intends to ensure $100 \%$ coverage of gigabit network (from $59 \%$ at present) and $5 \mathrm{G}$ (from $14 \%$ at present) at the European level.

Another direction of action for this objective is to increase the production of semiconductors, from $10 \%$ to at least $20 \%$, and by that, to elevate EU's contribution to the word production.

Addressing the need to adapt the European businesses to the digital area implies, according to the programme, to reach the level of $75 \%$ in cloud computing services, big data and artificial intelligence. In this endeavour, the EU member states will benefit of start-ups.

The target for the digitalization of public services is to ensure extended online access, up to $100 \%$, to essential public services such as those related to work, school, day-to-day life basic processes.

The European Union is ready to assist the member states in their effort to contribute to European digitalization by facilitating investments and funding specific projects. An important instrument in the digital transformation of the European Union will be the multi-country projects in different digital-related domains, for which the EU will setup a mechanism of cooperation and coordination and the European Digital Infrastructure Consortium to assist and facilitate their implementation.

The European digitalization process will be monitored and evaluated on an annual basis until 2030, which is the term established for its accomplishment.

In addition to the European digitalization, the EU is more and more committed to the technology dimension of the European Defence project, seen as an important part of the greater endeavour to strengthen the EU' strategic autonomy and role in the international environment. In recent years the EU has significantly developed the European defence project by the rapid operationalization of its main instruments, the Coordinated Annual Review on Defence, Permanent Structured Cooperation and the European Defence Fund, and an important component of this effort is the domain of development, research and innovation.

\section{Conclusions}

The new technologies' advance and their major influence on the production system, management and governance indicate that we are witnessing the Forth Industrial Revolution.

The development of emerging and disruptive technologies implies both benefits and challenges that need to be addressed. Beyond the general advantages related to extended access to information, mobility, communication, and cost efficiency, to name a few, individuals, society and countries face at different levels, but to a certain degree, the vulnerability generated by the new technologies' misuse, while the risks associated tend to intensify against the background of minimal regulations and norms internationally accepted and assumed.

Relevant states and international organizations are increasingly preoccupied to define strategies and policies on new technologies in order to ensure the positive outcomes and mitigate the negative effects of their use.

Moreover, new technologies tend to become a competition zone for major actors in the international arena so that states and organizations are preparing to put a great effort in this domain to accomplish strategic goals.

The United Nations, the United States and the European Union are three important international actors who have taken the first steps in addressing the new technologies 
domain. Despite significant differences of their approaches, all three aim at maximizing the advantages they possess and those offered by the new technologies and minimizing the challenges and risks.

The prestige of the United Nations as the protector of UN Charter's principles and values determines "Secretary-General's Strategy on New Technologies" focus on promoting the conformity of the new technologies use with human rights, fundamental freedoms and the international law. Guided by the intention to protect and promote the global values, stimulate inclusion and transparency, the United Nations assumes to support the process of establishing international policies and norms of new technologies for the beneficial use of them, with minimum risk for society, economy and security.

To this end, the United Nations will capitalize its global power to increase awareness, sustain dialog on normative and cooperation frameworks and assist government capacity development.

The United States is mainly concerned with the challenges originating from its strategic competitors, namely China and Russia, and their potential to surpass US' leadership in certain areas of new technologies.

In this context, "The National Strategy for Critical and Emerging
Technologies" aims at maintaining US' global leadership in the highest-priority technology domains, increasing cooperation with allies and partners in relevant areas of new technologies, and managing the risks associated to emerging and disruptive technologies.

In order to achieve these objectives the United States will concentrate on two pillars, namely promoting the national security innovation base and protecting US' advance by domestic endeavour and common effort with allies and partners.

The European Union is preparing for the Digital Decade putting in centre European citizens and their digital skills, the digital infrastructure, the digital businesses, and the public services' digitalization. Specific ambitious targets have been set up in all four domains.

At the same time, the EU is working on developing new instruments of assistance and financial support to increase the contribution of the member states to the achievement of the targets assumed by "A path to the Digital Decade" programme.

Simultaneously, development, research and innovation are increasingly important within the European Defence project, as part of EU's greater goal to consolidate its autonomy and international relevance.

\section{REFERENCES}

Armstrong, P. (2017). Disruptive Technologies: Understand, Evaluate, Respond. Available at: https://books.google.ro/books?hl=en\&lr=\&id=WNm DgAAQBAJ\&oi=fnd\&pg=PP1\&da $=$ emerging + and + disruptive+technologies\&ots $=\mathrm{C}$ Q-.

European Commission. (2021). A path to the Digital Decade: common governance and coordinated investment for the EU's digital transformation by 2030, Factsheet, available at: https://op.europa.eu/en/publication-detail/-/publication/b8937194-19b8-11ec-b4fe-01aa75 ed71a1/language-en.

European Commission. (2021). The Communication Digital Compass: The European Way for the Digital Decade, available at: https://digital-strategy.ec.europa.eu/en/policies/ europes-digital-decade. 
Frunzeti, T., \& Alexandru, A. (2021). The United States - China Strategic Competition - Implications for the Transatlantic Relations. International Conference "Education and Creativity for a Knowledge Based Society", $15^{\text {th }}$ Edition, Section 9 - Communication, International Relations, Language, Culture and Civilization, Education Sciences.

Schwab, K. (2016). The Fourth Industrial Revolution: what it means, how to respond. Available at: https://www.weforum.org/agenda/2016/01/the-fourth-industrial-revolutionwhat-it-means-and-how-to-respond/.

The President of the United States. (2020). Pillars of Success. 5-10.

The President of the United States. (2020). The National Strategy for Critical and Emerging Technologies, Introduction. 1, available at: https://trumpwhitehouse. archives.gov/wp-content/uploads/2020/10/National-Strategy-for-CET.pdf.

The President of the United States. (2020). World Leader of Critical and Emerging Technologies. Introduction, 2-3.

United Nations. (2018). New technologies and a new frontier for the UN.

United Nations. (2018). Secretary-General's Strategy on New Technologies, 1.1 Principles Guiding UN Engagement. Available at: https://www.un.org/en/newtechnologies/images/pdf/SGsStrategy-on-New-Technologies.pdf.

United Nations. (2018). Strategic Commitments. 1.2, 13. 